\title{
Silencing of HEPN1 is Responsible for the Aggressive Biological Behavior of Pituita Somatotroph Adenomas
}

Hu Peng ${ }^{a}$ Jingping Fan ${ }^{a}$ Jian Wu Juntian Lang ${ }^{a}$ Junyu Wang Shuwei Zhao ${ }^{a}$ Jianchun Liao

aDepartment of Otolaryngology - Head and Neck Surgery, Chang' 'ospital, Medical University, Shanghai, 'Department of Neurosurgery, Chan Medical University, Shanghai

Key Words
HEPN1 • Pituitary somatotroph

\section{Abstract}

Background/Aims: The progression, and invasic genes, we selected Results: We us gr -wide differential expression analysis in 15 invasive and invasive som tc iro 10 momas. HEPN1 reduction was more frequent in the invasive group, and this re was irmed by qRT-PCR. To understand the function of HEPN1, the pituitary ade noma lines, GH3 and GT1.1, were stably transfected with short hairpin RNA (shRNA) ta. $g H_{\llcorner}>$or ectogenic HEPN1 by lentivirus-mediated transfection. We found that HE. erexpression in GH3 and GT1.1 cells inhibited cell proliferation, induced apoptosis, at, ed invasive capacity, whereas HEPN1 silencing enhanced cell proliferation and II sinn accompanied by decreased apoptosis. Western blot analysis revealed that HEPN1 ve pression decreased MMP-2, MMP-9, and Bcl-2 expression, but increased BAX, p53, caspase-3 expression. In contrast, HEPN1 silencing increased MMP-2, MMP-9, and Bcl-2 expression, but decreased BAX, p53, and caspase-3 expression. Conclusion: Taken together, our results suggest that reduction of HEPN1 may play an important role in the progression of pituitary somatotroph adenomas. HEPN1 may thus be a candidate as a prognostic predictor or an anticancer therapeutic target for patients with somatotroph adenoma. 


\section{Introduction}

Pituitary adenomas, including somatotroph adenomas, constitute $10-15 \%$ of intracranial neoplasms [1]. Somatotroph adenomas are one of the most common types of pituitary adenomas, second only to prolactinomas [2]. With the exception of prolactinomas, surgical resection is the most effective treatment method for pituitary adenomas. Althoug' pituitary adenomas are benign, some pituitary adenomas are considered to be aggressiv or invasive, showing atypical behavior, such as invading adjacent tissues and proliferating rapidly [3]. Invasion of surrounding structures by pituitary adenomas increases the diffir of complete resection and is an important reason for post-operative recurrence [4-6]. At several biological markers for the aggressive manner of pituitary adenor investigated, none of these factors are widely accepted as being responsible for ; of pituitary adenomas $[7,8]$, and the pathogenic mechanisms underlying vary noma formation, progression, and invasion remain poorly understood. Mu is in assic oncogenes and tumor suppressor genes (TSGs), which might be prog sti ctors or gene therapy targets, are rarely found in pituitary tumors [9-11], th rther hrvestigation of new oncogenes and TSGs is needed.

To study the candidate oncogenes and TSGs involved i adenomas, we selected somatotroph adenomas as repres Twenty-seven human somatotroph adenomas were select. adenomas and 12 were non-invasive, according to the modifie have used Affymetrix HG-U133 plus 2.0 arrays entify gene. vith different transcription levels between invasive and non-invasive aden and normal pituitary tissues. The results of genome-wide differential expression ar ave not been previously reported. Aberrant reduction in transcription of hepatoce ar a moma, down-regulated 1 (HEPN1), a novel candidate TSG, has been observer inv omatotroph adenomas. HEPN1 gene maps to the 3'-noncoding region of HE $C$ gene. While the expression of HEPACAM was downregulated or undetectable in mar ell lines, there is only one previous study on HEPN1 [13]. HEPN1 was first i ea cumorous liver, and downregulated in human hepatocellular carcinoma [13 n transfected into HepG2 cells, HEPN1 reduces cell viability and induces apoptocic $[13$, , silencing HEPN1 is associated with carcinogenesis of hepatocytes [13]; hov $\alpha$, the mechanism underlying the anti-tumorigenesis effect of HEPN1 has not been det nine

We have studied the of HEPN1 in pituitary adenoma cell lines (GH3 and GT1.1). We demonstrate or propN1 promotes the proliferation and invasiveness of pituitary adenoma cells, hi cing apoptosis, thus underscoring the importance of HEPN1 in tumorigene an sion and defining HEPN1 as a promising molecular target for gene therapy.
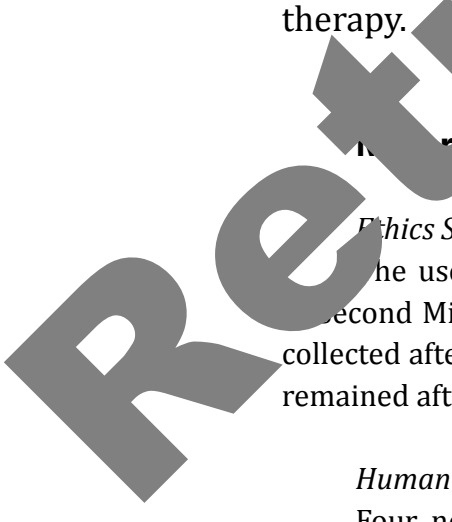
's and Methods

\section{hics Statement}

he use of Human tissue specimens was approved by the institutional research ethics committee cond Military Medical University. All patients provided written informed consent, and samples were collected after surgical resection. All tissue samples included in this study were collected from tissues that remained after the completion of diagnosis and are otherwise discarded.

\section{Human pituitary tissues and adenomas}

Four normal human adenohypophyses were obtained at the time of autopsy from patients with no evidence of endocrinopathies. Histologic examinations were performed to exclude the possibility of incidental pathologies. Fifteen invasive somatotroph adenomas and 12 non-invasive adenomas were selected from our pituitary tumor tissue bank. All of the somatotroph adenoma specimens were obtained at the time of surgery at Changzheng Hospital (Shanghai, China). The patient sources did not receive sellar 
irradiation before tumor resection. All of the samples were frozen in liquid nitrogen and stored at $-80^{\circ} \mathrm{C}$. The tumors were characterized based on the clinical, radiologic, histologic, and immunohistochemical features. Tumor size and invasiveness were defined on the basis of pre-operative radiologic studies and operative findings, and a modification of the Hardy classification [12], as follows: grade I tumors were microadenomas ( $<1 \mathrm{~cm}$ in diameter); and grade II tumors consisted of enclosed macroadenomas $(>1 \mathrm{~cm}$ in diameter) with or without suprasellar extension. Both grade I and II tumors were defined as non-invasive. Grade III tumor exhibited local invasiveness with evidence of bony destruction and tumor within the sphenoid and/a cavernous sinus (CS). Grade IV tumors demonstrated CNS/extracranial spread with or without metastases. Grade III and IV tumors were considered to be invasive. Because there might be small defects in the $\mathrm{m}$ wall of the CS, non-invasive pituitary adenomas are able to grow into the CS through defects and s $N$ an illusion of CS invasion [14]. Therefore, CS "invasion" on MRI was not considered a suffici cond for invasion in the current study. Of the 27 tumors, 7 were grade I, 5 were grade II, 6 were grade grade IV.

\section{Microarray preparation and data generation}

Total RNA was isolated from 27 somatotroph adenomas and 4 norme uitaries asing TRIzol (Invitrogen), and then cleaned up with a QIAGEN RNeasy minikit according manufacturer. RNA was quantified by spectrophotometry and RN Bioanalyzer (Agilent Technologies, Santa Clara, CA). Microarray tar wo red and labeled from 300 ng of total RNA using the MessageAmp premier RNA amplificatic ppiced Biosystems/Ambion, Austin, TX) following the manufacturer's instructions. Affymetrix HG-U1 us 2.0 arrays (Santa Clara, CA) were hybridized with $10 \mathrm{~g}$ of cRNA and processed and ned using sta ard Affymetrix protocols. RNA integrity was confirmed and cDNA was transcribed, labele hybridized from individual samples on the Affymetrix Human Genome U133 Plus 2.0 arrays.

Quantitative reverse transcriptase-polymero hat.

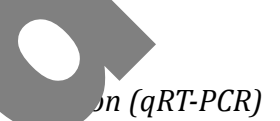

Total RNA, including the total RNA from 10 al pituitary tissues (BioChain Institute, Hayward, CA, USA) as a positive control, was reverse-tran ig a MLV transcriptase (Invitrogen, Carlsbad, CA, USA) with oligo(dT)12-18 primers og reverse transcripts were used as templates for the analysis of gene expression using a cycler (Takara Shuzo, Kyoto, Japan) and KOD-plus-polymerase (Toyobo, Osaka, Japan). The primerc wer ows: 5'-ATT GCC CTC TCT CCT CAC ACA GTA G-3'(forward); and 5'-ACA ATC ACA CTA ATC C-AGACGG-3'(reverse). The PCR conditions were as follows: 2 min at 94 ${ }^{\circ} \mathrm{C}$, followed by $25-35$ cycles $\quad 94{ }^{\circ} \mathrm{C} \quad 30 \mathrm{~s}$; $30 \mathrm{~s}$ at $58-68{ }^{\circ} \mathrm{C}$; and a final elongation step at $68{ }^{\circ} \mathrm{C}$ for $60 \mathrm{~s}$. PCR products were separate agarose gel and visualized by ethidium-bromide staining. The band intensity was quant CS mralyzer 2.0 (ATTO, Tokyo, Japan).

HEPN1 t nsec no a silencing in GH3 and GT1.1 cells

Rat $C$ and $n$ GT1.1 pituitary adenoma cells were obtained from the Chinese Academy of Sci cer (Sh רi, China). Cells were maintained in DMEM/F12 + 10\% FBS supplemented with $100 \mathrm{U} / \mathrm{ml}$ of $\mathrm{p} \quad \mathrm{in}$ an $\mathrm{U} / \mathrm{ml}$ of streptomycin, and incubated at $37{ }^{\circ} \mathrm{C}$ and $5 \% \mathrm{CO}_{2}$.

the THM virus vector (Invitrogen) to construct Lenti-HEPN1 and Lenti-HEPN1 shRNA. Conditioned f Aly containing lentiviruses was harvested $48 \mathrm{~h}$ after transfection of HEK293T cells. This medium was ite and used to infect recipient cells in the presence of $10 \mu \mathrm{g} / \mathrm{ml}$ of polybrene.

Protein extraction and Western blotting

Proteins were extracted from subconfluent cultures and subjected to Western blot analysis. After blocking with 5\% non-fat milk in phosphate-buffered saline with Tween (PBS-T) for $1 \mathrm{~h}$ at room temperature, the membranes (Protran; Schleicher \& Schuell, Dassel, Germany) were blotted with primary antibody, followed by incubation with a peroxidase-conjugated secondary antibody, as described previously [15]. Bound antibodies were visualized using enhanced chemiluminescence (Bio-Rad, Richmond, CA, USA). The primary antibodies used were as follows: rabbit polyclonal antibody to HEPN1; mouse monoclonal antibody to $\mathrm{p53}$; goat polyclonal antibody to BAX; goat polyclonal antibody to caspase-3; mouse monoclonal antibody to $\mathrm{Bcl}-2$; goat polyclonal antibody to matrix metalloproteinase (MMP)-2; mouse monoclonal antibody to 
MMP-9; and a rabbit polyclonal antibody to $\beta$-actin used as a gel loading control. These antibodies were purchased from Santa Cruz Biotechnology, Inc. (Santa Cruz, CA, USA).

\section{Cell proliferation assay}

Cell growth was determined by the 3-(4,5-dimethylthiazol-2-yl)-2,5-diphenyltetrazolium bromide (MTT) colorimetric assay. Non-transfected GH3 and GT1.1 cells and stably transfected cells (Lenti-HEPN 1 Lenti-shRNA, and Lenti-GFP) were replated onto 96-well plates at $4 \times 10^{3}$ cells/well and cultured overnigh to allow for cell attachment. At daily intervals $(24,48,72,96$, and $120 \mathrm{~h}$ ), the number of viable cells was determined by MTT assay. Briefly, cells were incubated with $0.2 \mu \mathrm{g} / \mathrm{ml}$ of MTT for $4 \mathrm{~h}$ in the dark at After removal of the medium, the formazan crystals produced from MTT by live cells were dissolver $\mu \mathrm{l}$ of dimethyl sulfoxide (DMSO), and the absorbance was measured at $570 \mathrm{~nm}$ with an Ultr dltifu microplate reader (Tecan, Durham, NC, USA). Three independent experiments were quadruplicate wells.

\section{Apoptosis assay}

Apoptosis was measured using an Annexin V/propidium iodide (PI) apop detectio- Kit (Bender MedSystem, Vienna, Austria). Briefly, cells cultured in 6-cm dishes were trypsinı vashed, stained with PI-conjugated anti-Annexin $\mathrm{V}$ antibody under darkness for $15 \mathrm{~min}$, mpera flow cytometry (FACSCalibur; Becton-Dickinson, Mountain View, CA,

\section{Invasion assay}

An equal number $\left(1 \times 10^{5}\right)$ of non-transfected cells Lenti-HEPN1, or Lenti-GFP, were plated onto separate 2 ll cell culture inserts coated with Matrigel with 8- $\mu \mathrm{m}$ pores. Minimum essential medium (MEM) BS was added to the lower chamber as a chemoattractant. After a $24-\mathrm{h}$ incubation at $37^{\circ} \mathrm{C}$ und $5 \%$ atmosphere, cells remaining adherent to the upper surface of the filter were removed usin cot. icator. The cells on the lower surface of the membrane (the migrated cells) were fixed wit ormaldehyde, stained with hematoxylin, and counted. The invasion rate was determined from thre

\section{Statistical Analyses}

All data are expressed as tho mea indard deviation (SD) of three independent experiments. Statistical analysis between wo groups was performed using Student's t-test, and the comparison between three or more gro was formed using analysis of variance (ANOVA) analysis, followed by Dunnett's t-test. $\mathrm{P}<0.05$ was d statistically significant.

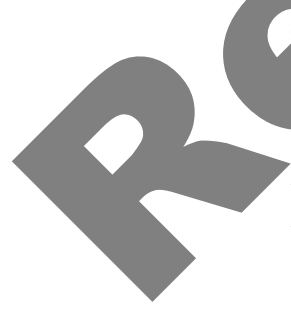

12. vive somatotroph adenomas and 28.5 in noninvasive somatotroph adenomas

1A) next analyzed the expression of the HEPN1 gene by qRT-PCR in 27 human S a atotroph adenomas and 4 normal pituitary tissues. The median level of HEPN1 mRNA xp sion(HEPN1/ $\beta$-actin) was 1.2 (range, 1.1-1.3) in normal pituitary tissues. We classified is of expression of $<$ one-half this value (HEPN1/ $\beta$-actin $<0.6)$ as significant reduction. Reduced expression of HEPN1 was detected more frequently in invasive adenomas than in non-invasive adenomas (Fig. 1B) and HEPN1 mRNA expression was significantly lower in invasive adenomas than in non-invasive adenomas (Fig. 1C).

Effects of Lenti-HEPN1 or Lenti-shRNA on HEPN1 expression

After transfection, qRT-PCR analysis for HEPN1 expression demonstrated a 7.6-fold increase in HEPN1 transcripts in GH3 cells stably transfected with Lenti-HEPN1 and a 6.5-fold increase in stably transfected GT1.1 cells compared with non-transfected parental controls 


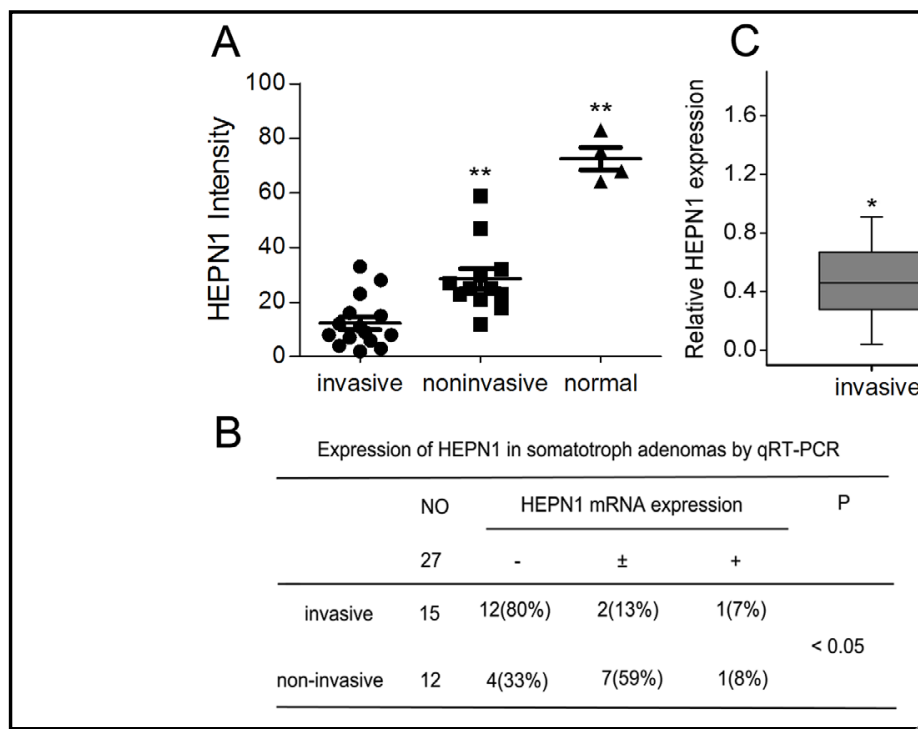

Fig. 1. Level of expression of HEPN1in somatotroph adnomas and nc expression levels assessed by using Affymetrix U133plus2.0 micr adenomas, 12 non-invasive adenomas and 4 normal pituitaries. The av invasive adenomas or noninvasive adenomas was signifj 'ntly lower tha 0.01). (B) Reduced expression of HEPN1 was detected frequently in invasive adenomas than in noninvasive adenomas $\left(80 \%\right.$ vs. $\left.33 \%,{ }^{*} \mathrm{P}<0.05\right)$. -, signific wer expression of HEPN1 mRNA;, $\pm 0.6 \leq$ HEPN $1 / \beta$-actin $\leq 1.2$; and HEPN $1 / \beta$-actin $>1.2$. (C) $\mathrm{N} 1$ expression in the invasion group was significantly lower than the non-invasion group $(* \mathrm{P}<0$

Fig. 2. Effects of Lenti-HEPN1 and Lenti-shRNA transfection on HEPN1 expression. (A) Quantitative RT-PCR analysis demonstrates $t^{\prime}$ HEPN1 mRNA was signif overexpressed in pituitary ar oma cells stably transfecter-mith HEPN1 and suppre a tuitary adenoma cells $s$ iy $r_{0}$ cted with Lenti-sh A c a with cells stabl sfecte. with Lenti$\mathrm{GF}$ pro in GH and GT1.1 cells was ex. jy Western blotting. c itr ${ }^{* *} \mathrm{P}<0.01$ as compared with he Atrol groups.
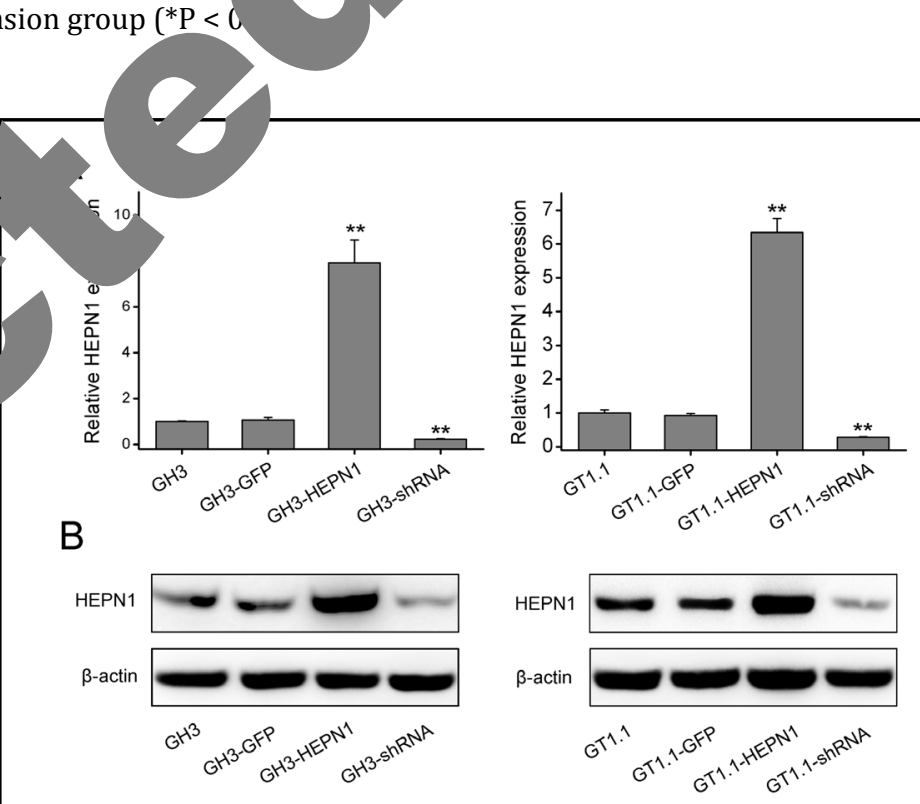

(Fig. 2A). Western blot analysis confirmed the increase in HEPN1 protein expression in GH3 Lenti-HEPN1 and GT1.1 Lenti-HEPN1 transfectants (Fig. 2B). In contrast, HEPN1 expression was reduced by $66.7 \%$ in GH3 Lenti-shRNA transfectants and 63\% in GT1.1 Lenti-shRNA transfectants compared with HEPN1 expression in the control cell lines (Fig. 2A). HEPN1 protein was reduced by $65.7 \%$ in GH3 Lenti-shRNA transfectants and 62\% in GT1.1 LentishRNA transfectants compared with HEPN1 expression in the control cell lines (Fig. 2B). 
A
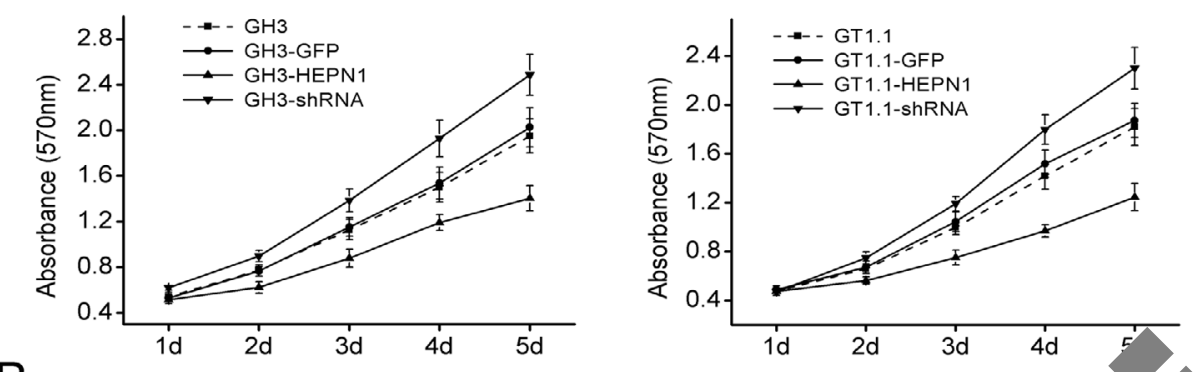

B
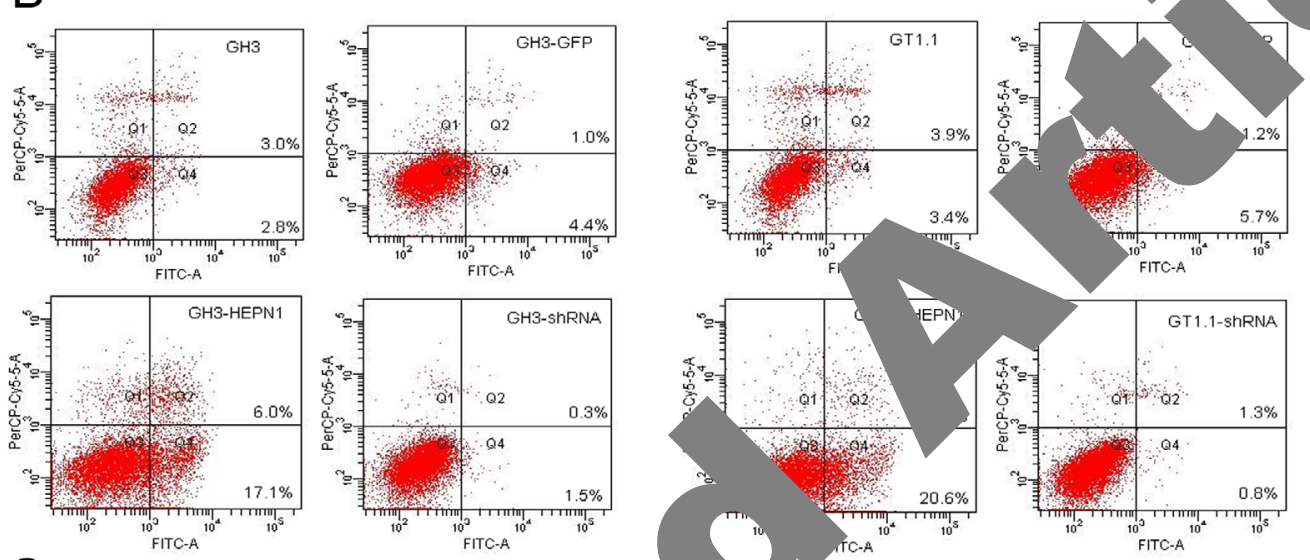

C
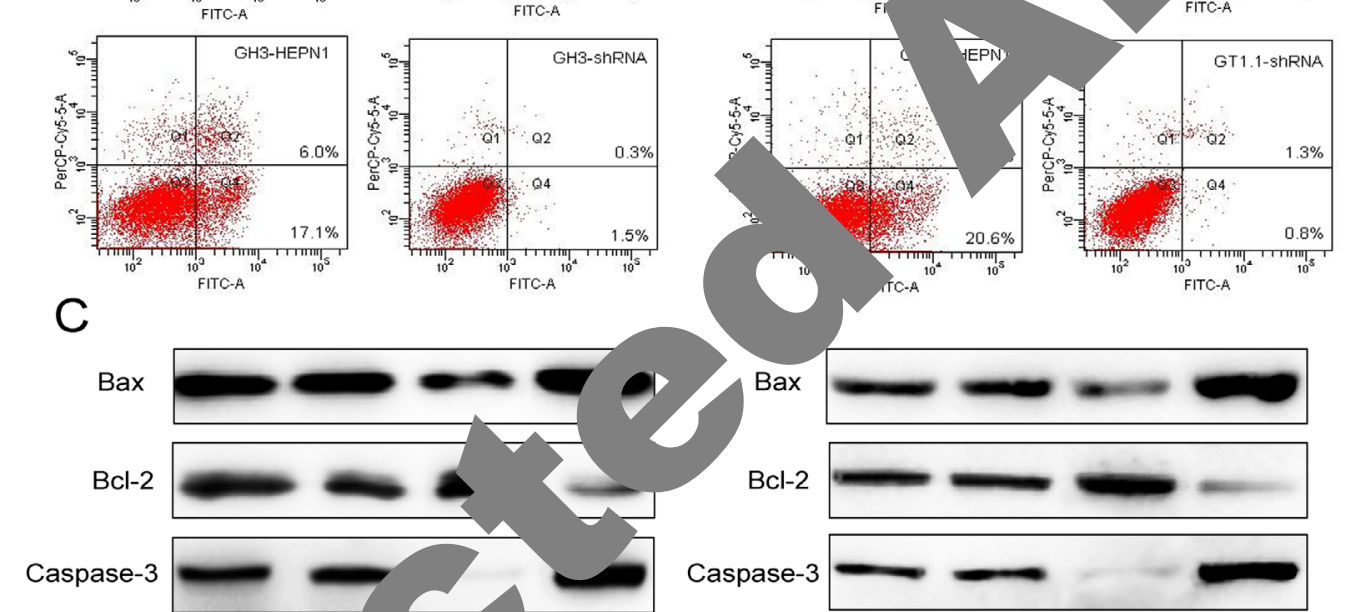

Caspase-3

Bcl-2

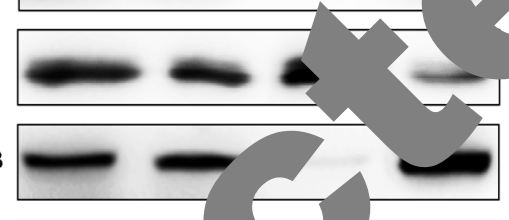

Caspase-3

p53

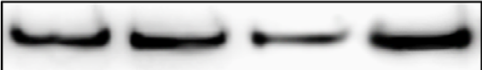

p53

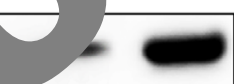

$\beta$-actin

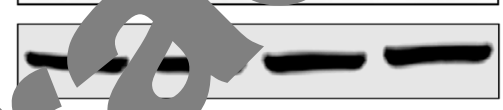

$\beta$-actin

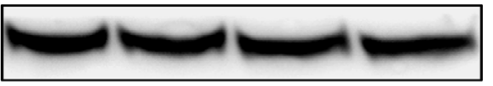

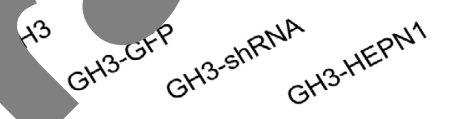

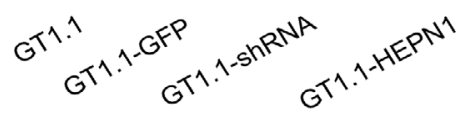

3.

of HEPN1 expression on pituitary adenoma cell proliferation and apoptosis. (A) Effect of

(H) $\sqrt{1} 1$ overexpression and underexpression on GH3 cell proliferation was measured by MTT assay.

bs ance was read at $570 \mathrm{~nm}$ with an average of triplicate wells. $\left({ }^{*} \mathrm{P}<0.05\right.$ at $48,72,96$, and $120 \mathrm{~h}$ for

-HEPN1 versus Lenti-GFP or non-transfected GH3 cells; ${ }^{*} \mathrm{P}<0.05$ at $48 \mathrm{~h}$, and ${ }^{* *} \mathrm{P}<0.01$ at 96 and 120

$\mathrm{h}$ for Lenti-shRNA versus Lenti-GFP or non-transfected parental GH3 cells). The results in GT1.1 cells were similar to GH3 cells. (B) Apoptosis in GH3 cells was measured by Annexin V/propidium iodide (PI) staining following Lenti-shRNA or Lenti-HEPN1 transfection. Early apoptotic cell populations were significantly increased $\left({ }^{* *} \mathrm{P}<0.01\right)$ after Lenti-HEPN1 transfection and decreased $\left({ }^{*} \mathrm{P}<0.05\right)$ after Lenti-shRNA transfection. The results in GT1.1 cells were similar to GH3 cells. (C) Western blotting analysis for p53, Bax, $\mathrm{Bcl}-2$, and caspase-3. Decreased expression of p53, Bax, and caspase-3 and increased expression of Bcl-2 were observed in GH3 and GT1.1 cells $72 \mathrm{~h}$ after Lenti-shRNA transfection as compared with the control groups $\left({ }^{*} \mathrm{P}<0.05\right)$. Increased $\mathrm{p} 53$, Bax, and caspase-3 and decreased Bcl- 2 was observed in GH3 and GT1.1 cells stably overexpressing HEPN1 $(* \mathrm{P}<0.05)$. 
A
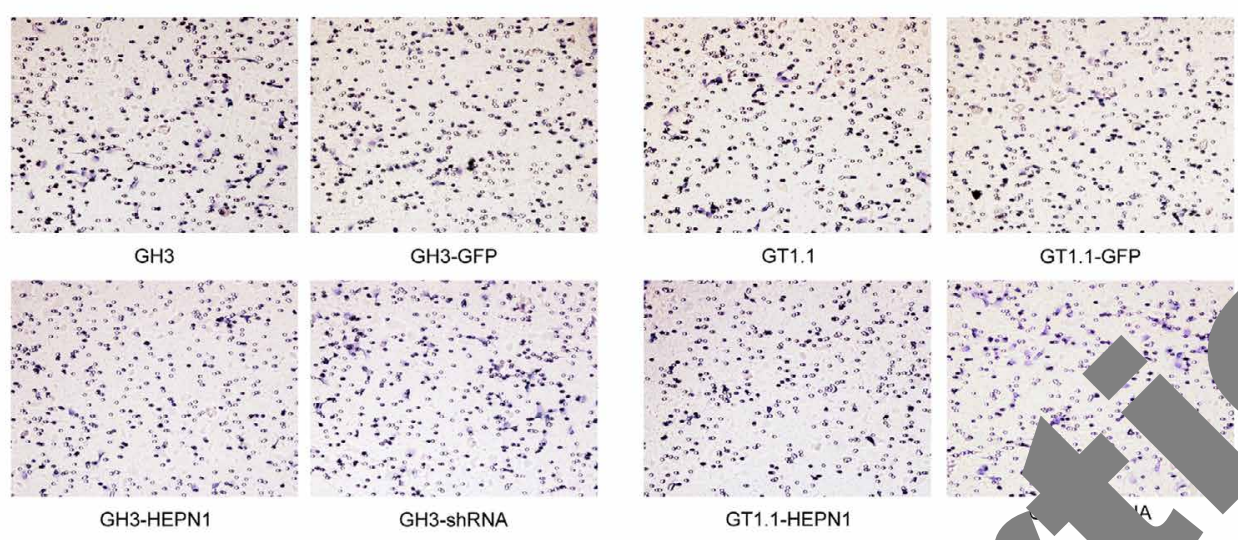

GT1.1-GFP

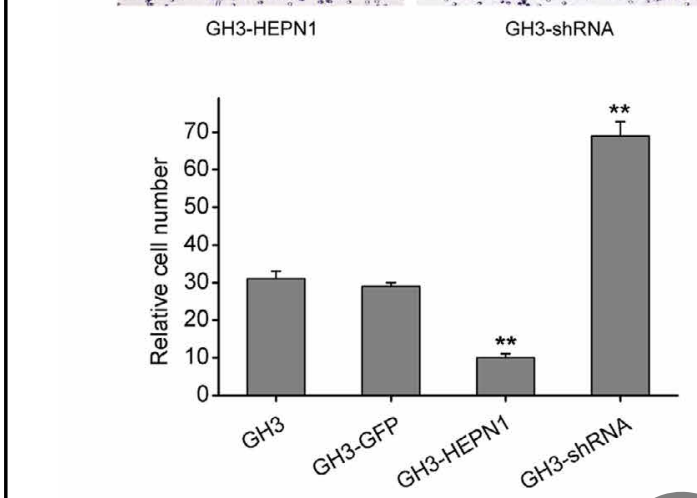

B
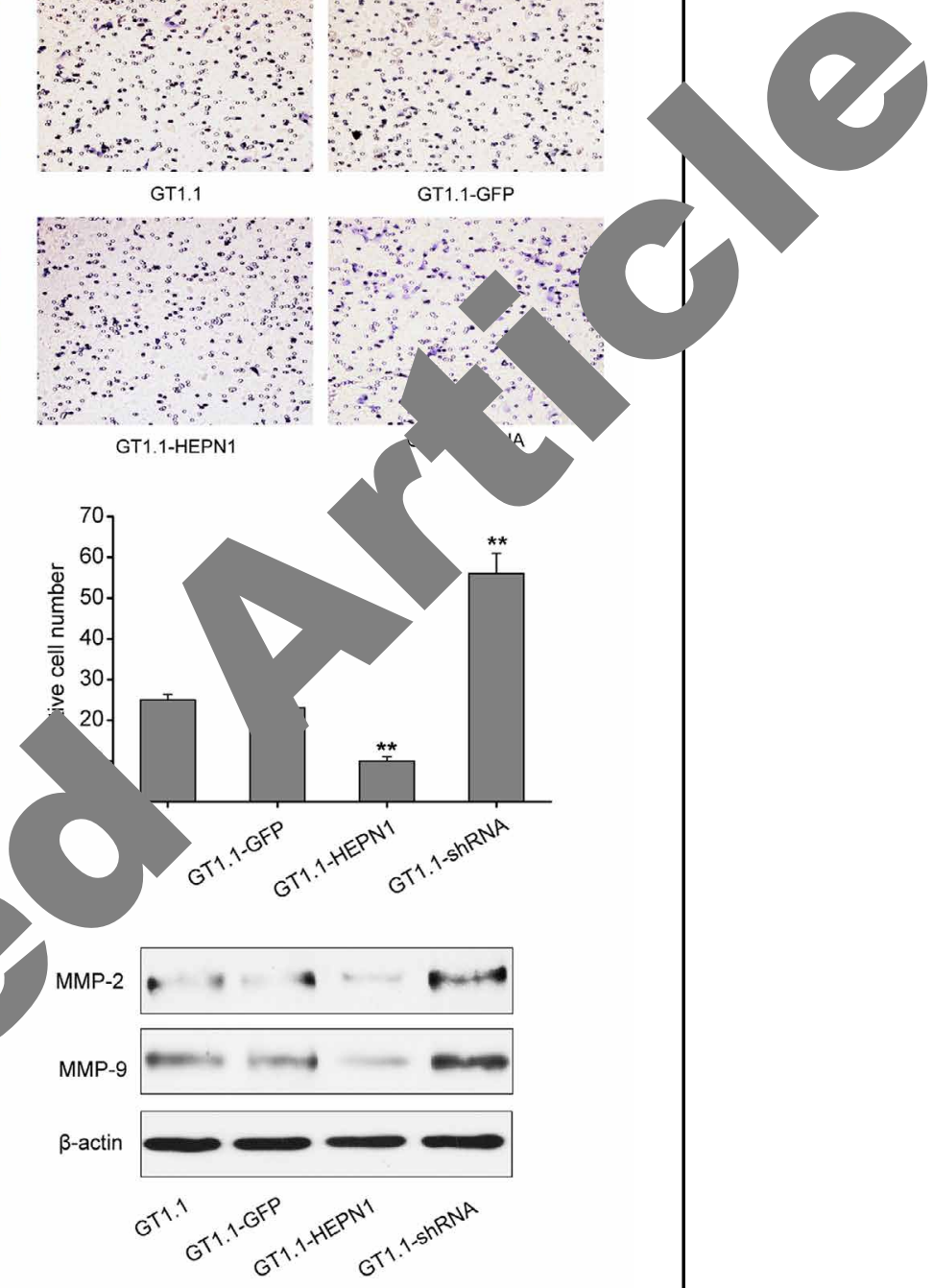

Fig. 4. HEPN1 pres $\mathrm{n} r$ gulates cell invasive capacity in the Matrigel model. (A) Matrigel assays showing the effect of ti-sh and Lenti-HEPN1 on the invasive potential of GH3 and GT1.1 cells. The bar graph ind te th number of invaded cells at $24 \mathrm{~h}$ after top-side cell seeding. The results demonstrated that Ler. PN1 s. essed invasion of GH3 and GT1.1 cells, while Lenti-shRNA potentiated invasion of GH3 ana $\quad$ compared with control groups $(* * P<0.01)$. (B) Western blot of MMP-2 and -9 expression. a 1 P-2 and -9 expression was observed in Lenti-HEPN1-transfected GH3 and GT1.1 cells, Wy ress Lenti-shRNA transfected cells exhibited increased MMP-2 and -9 protein expression $48 \mathrm{~h}$ after an ction. $\left({ }^{*} \mathrm{P}<0.05\right.$ and $\left.{ }^{* *} \mathrm{P}<0.01\right)$.

HEPN1 inhibits proliferation and induces apoptosis in GH3 and GT1.1 cells via improvement in $p 53$ expression

The proliferation of GH3 and GT1.1 cells was examined by MTT assay 2-5 days after transfection with lentivirus containing Lenti-shRNA, Lenti-HEPN1, Lenti-GFP, and nontransfected cells. Lenti-shRNA transfection promoted GH3 and GT1.1 cell growth. In contrast, Lenti-HEPN1 transfection suppressed GH3 and GT1.1 cell growth (Fig. 3A).

Also, flow cytometry (Annexin V-FITC-PI) was used to study the effect of Lenti-HEPN1 transfection on apoptosis. Lenti-shRNA transfection inhibited GH3 and GT1.1 cell apoptosis, while Lenti-HEPN1 transfection promoted GH3 and GT1.1 cell apoptosis (Fig. 3B). 
Because GH3 and GT1.1 cell growth was inhibited and apoptosis was induced by HEPN1, we further studied the HEPN1 effect on the level of p53, BAX, BCL-2, and caspase-3, which are related to apoptosis in GH3 and GT1.1 cell lines. After a 72-h transfection, a decrease in BAX, p53, and caspase- 3 and an increase in BCL- 2 were observed in Lenti-shRNA transfected GH3 and GT1.1 cells compared with the control groups. A decrease in BAX, p53, and caspase- 3 and an increase in BCL-2 were observed in Lenti-HEPN1 transfected GH3 and GT1.1 cell (Fig. 3C).

Reduction of HEPN1 promotes cell invasion might via an increase in MMP-2 an expression

To investigate the effect of HEPN1 inhibition or overexpression on pitu y ad cell invasion, Transwell migration was performed. Exogenous expression of HEP rea Transwell migration compared with the other transfected groups (Fig. 4 he of cell migration and infiltration that characterizes metastasis require se extra aular matrix (ECM) matrix metalloproteinases (MMPs), especially MMP-2 u ituitary adenomas, thus we examined the expression of MMP-2 and -9. As she in Fig. 4o, GH3 and GT1.1 cells transfected with Lenti-HEPN1 demonstrated sign; ificantly i ed MMP-2 and -9 protein expression, while Lenti-shRNA transfectants exhil pression. Thus, reduction of HEPN1 might increase MMP-2 and -9 expressic ory with the improved invasive capacity in the Matrigel invasion model.

\section{Discussion}

The mechanisms responsible for progres an avasion of pituitary adenomas are poorly understood. Mutations in classic d TSGs are rarely found in pituitary tumors [9-11], so identification of cand ate Acogenes and TSGs is an important method to understand pituitary tumorigeresis al as 1 .

Based on our results of $g$ been reported before, HEPN1, el candidate TSG, exhibited an aberrant reduction in transcription in invasive somatot denomas tissues. Before our study, others have reported microarray ana used in somatotroph tumors. In the study of Evans et al. [16], there is no details abou EPN However, HEPN1 is a gene that identified in 2003 [13], so it is possible that Ev mplementary DNA (cDNA) microarray analysis may not include HEPN1. I ydy or Morris et al. [17], they used Affymetrix GeneChip HG-U133A in a total of fiv hi tic tuitary adenomas of each of the main subtypes (somatotroph adenoma, $p$ acti $m$, corticotropinoma, and non-functioning pituitary adenoma) and 5 normal b n pic ry autopsy specimens. The cyclin-dependent kinase inhibitor 2C, or p1 w $\mathrm{s}$-expressed in the somatotroph adenoma, prolactinoma and non-functioning pit vade ia arrays. However, in the realtime quantitative PCR (RQ-PCR) analysis, and p1or $n$ significantly under-expressed in corticotropinomas. HEPN1 was not included e 9. genes under-expressed $\geq 2$.0-fold. This difference between the study of Morris $e^{\prime}$ al and ours may attribute to the diference of tumor samples or experimental error of nif array. The microarray results were further confirmed by q-RT-PCR, suggesting that N1 reduction may have significant value in somatotroph adenoma tumorigenesis and invasion. Another possibility is that the down-regulation of HEPN1 somatotroph adenomas is a consequence of HEPN1 being poorly expressed in GH-secreting cells generally, as the normal pituitary contains a mixed population of cells. Immunohistochemistry studies may exclude this possibility, but there is no commercial product of HEPN1 antibody used for immunohistochemistry at present. There are no previous reports on the effect of HEPN1 in pituitary adenomas. To understand the function of HEPN1 in pituitary somatotroph adenomas, we overexpressed HEPN1 in murine pituitary adenoma cell lines (GH3 and GT1.1). When transfected into pituitary adenoma cells, HEPN1 reduced cell viability, 
induced apoptosis accompanied by enhanced expression of BAX, p53, and apoptotic effector caspase-3, and inhibited expression of anti-apoptotic Bcl-2. Conversely, HEPN1 silencing by Lenti-shRNA transfection inhibited cell apoptosis, promoted cell growth accompanied by inhibited expression of apoptotic factors Bax, p53, and caspase-3, and enhanced expression of anti-apoptotic factor Bcl-2 [18]. It is widely accepted that Bax [18], p53 [19], caspase-3 [20] and Bcl-2 [18] play an important role in regulating apoptosis. These results suggest th? loss of HEPN1 may contribute to somatotroph adenoma growth by apoptosis inhibition.

Furthermore, in GH3 and GT1.1 cells, HEPN1 inhibited cell invasion with MMP-2 and -9 downregulation. In contrast, HEPN1 silencing by Lenti-shRNA transfection promoted invasion with increased expression of MMP-2 and -9. Remodeling of the ECM is conside $d$ an important step in pituitary tumor invasion and angiogenesis $[21,22]$. MMPs c2 iegra nd reorganise the ECM. In addition, the capsule of pituitary tumors is enclosed by dur bile is mainly composed of type IV collagen. MMP-2 and -9 which are both ty ${ }^{\prime}$ con capable of promoting tumor invasion by breaking down the basement $\mathrm{m}$ [23]. Gong et al. [7] showed that MMP-9 expression can be used to disti uris ve from non-invasive pituitary tumors, and reflect the extent of invasivene according to tumor subtype, size, and extension. Liu et al [24] re $\mathrm{P}_{\mathrm{P}}$ that MMP-2 is associated with aggressiveness and invasion in pituitary bu tumor size or secretory function. In the present study, we demonstrated to of HEPN1 leads to enhanced invasive capacity in GH3 and GT1.1 cells, possibly gh increased expression of MMP-2 and -9.

Collectively, these findings demonstrate as a TSG through suppression of proliferation a In conclusion, silencing of HEPN1 may contri pituitary somatotroph adenomas. In pituitary a proliferation, inhibits apoptosis by decr a promotes invasiveness by increasing t $3 \mathrm{AX}$, and caspase-3 expression, and promotes invasiveness by increasing t' ex ession of MMP-2 and -9. Our study indicates that HEPN1 might be a potential pro with invasive somatotroph ade s; isurther investigations are required to study the details of the effect of HEPr vituitary adenoma progression.

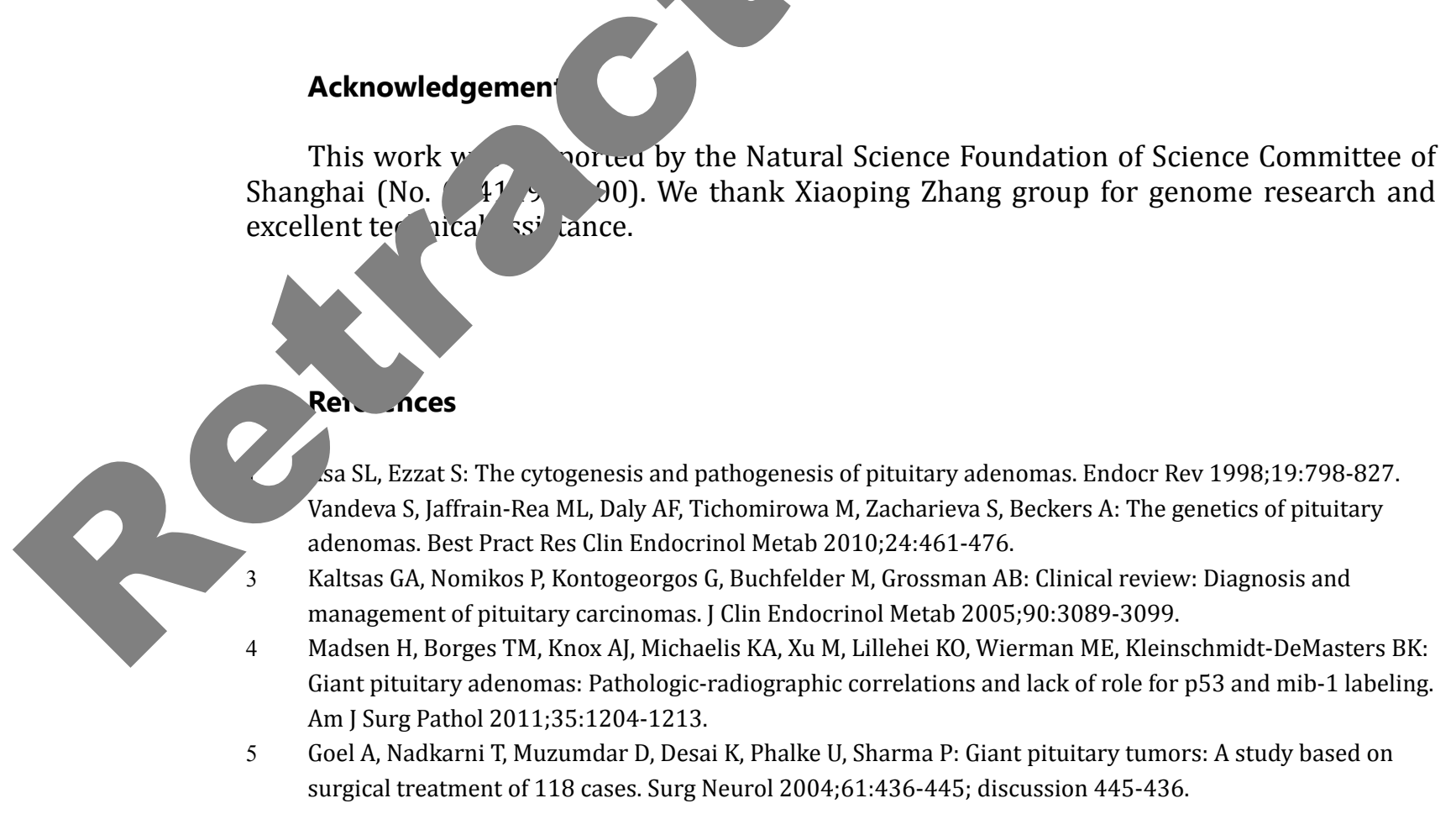




\section{Cellular Physiology Cell Physiol Biochem 2013;31:379-388 and Biochemistry \\ Peng/Fan/Wu/Lang/Wang/Liu/Zhao/Liao: HEPN1 in Somatotroph Adenomas}

6 Webb SM: Pituitary tumors: Coping with 'cured' pituitary tumors. Nat Rev Endocrinol 2011;7:251-252.

7 Gong J, Zhao Y, Abdel-Fattah R, Amos S, Xiao A, Lopes MB, Hussaini IM, Laws ER: Matrix metalloproteinase-9, a potential biological marker in invasive pituitary adenomas. Pituitary 2008;11:3748.

8 Salehi F, Agur A, Scheithauer BW, Kovacs K, Lloyd RV, Cusimano M: Biomarkers of pituitary neoplasms: A review (part ii). Neurosurgery 2010;67:1790-1798; discussion 1798.

9 Asa SL, Ezzat S: The pathogenesis of pituitary tumors. Annu Rev Pathol 2009;4:97-126.

10 Melmed S: Pathogenesis of pituitary tumors. Nat Rev Endocrinol 2011;7:257-266.

11 Dworakowska D, Korbonits M, Aylwin S, McGregor A, Grossman AB: The pathology of pituitary adenor from a clinical perspective. Front Biosci 2011;3:105-116.

12 Qian ZR, Sano T, Yoshimoto K, Yamada S, Ishizuka A, Mizusawa N, Horiguchi H, Hirokawa Inactivation of rassf1a tumor suppressor gene by aberrant promoter hypermethylation in hi adenomas. Lab Invest 2005;85:464-473.

13 Moh MC, Lee LH, Yang X, Shen S: Hepn1, a novel gene that is frequently down-regulat, carcinoma, suppresses cell growth and induces apoptosis in hepg2 cells. J Hepatol

14 Yokoyama S, Hirano H, Moroki K, Goto M, Imamura S, Kuratsu JI: Are nonfunctic pituitaly denomas extending into the cavernous sinus aggressive and/or invasive? Neurnsurgery 2 9:857-863.

15 Pscherer A, Schliwka J, Wildenberger K, Mincheva A, Schwaenen C Stilge Antagonizing inactivated tumor suppressor genes and activated on nes catile transgenesis system: Application in mantle cell lymphoma. FASEB J 2006;20:1188

16 Evans CO, Young AN, Brown MR, Brat DJ, Parks JS, Neish AS, Oyesiku N vel patterns of gene expression in pituitary adenomas identified by complementary $\quad$ ribonucleic a microarrays and quantitative reverse transcription-polymerase chain reaction. J Clin crinol Metab 2001;86:3097-3107.

17 Morris DG, Musat M, Czirjak S, Hanzely Z, Lillington its M, Grossman AB: Differential gene expression in pituitary adenomas by oligonucleotid ay a ois. Eur J Endocrinol 2005;153:143-151.

18 Sambaziotis D, Kapranos N, Kontogeorgos G: $C$ - 2 and bax with apoptosis in human pituitary adenomas. Pituitary 2003;6:127 pituitary adenomas. Pituitary 2003;6:127 Opin Cell Biol 2005;17:631-636

20 Ikeda M, Hirabayashi S, Fujiwar? Ras-association domain familv nroter. ces apoptosis via both caspase-dependent and caspaseindependent pathways. E Res 200\%;313:1484-1495.

21 Paez-Pereda M, Kuchen er F, A E, Stalla GK: Regulation of pituitary hormones and cell proliferation by components of the ex matrix. Braz J Med Biol Res 2005;38:1487-1494.

22 Sang QX: Comp ${ }^{\prime}$ manx metalloproteinases in angiogenesis. Cell research 1998;8:171-177.

23 Stetler-Steve ny a, a LA, Kleiner DE Jr: Extracellular matrix 6: Role of matrix metalloproteinases in tumor in ion a $\mathrm{m}$ astasis. FASEB J 1993; 7:1434-1441.

24 Liu W sumo kada M, Miyake K, Kunishio K, Kawai N, Tamiya T, Nagao S: Matrix metalloproteinase 2.nd ssion correlated with cavernous sinus invasion of pituitary adenomas. J Med Invest 5;52: 58 . 